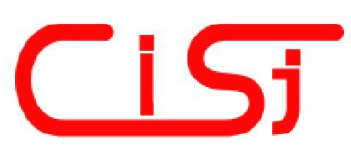

\title{
MANAGEMENT OF PROJECTS FOR ORGANIZATION DEVELOPMENT ON THE BASIS OF ENTREPRENEURSHIP
}

\author{
Sergey D. Bushuyev, Magomed Zh. Ozdoyev \\ Kyiv National University of Construction and Architecture \\ Povitroflots'kyi avenue, 31, Kyiv, 03680, Ukraine \\ sbushuyev@ukr.net
}

\begin{abstract}
The success of organization development projects depends on the competence of organizations in managing of its projects and entrepreneurship that is formed by the leadership of the organization which support progress towards successful completion of the projects. Entrepreneurial energy is generated and reproduced through internal and external sources. Set of entrepreneurial energy sources mathematically modelled by means of a set equipped with additional mathematical structures (metrics, topology, etc.). The studies is formulated as a project management for the development of organizations through the creation and reproduction of entrepreneurial energy of the parties concerned under operational and project activities of the organization in order to build effective mechanisms for the development of the organization. System model of development projects in a general approach to the use of business energy that will include absolutely heterogeneous concept reflecting energy sources. The structure of entrepreneurial energy is multidimensional. The main factors that shape the classification system of entrepreneurial energy are: types of entrepreneurial energy, sources and types of energy carriers, catalysts and inhibitors of the application of entrepreneurial energy in development projects, as well as indicators of the impact of the projects context. Copyright $(\mathbb{C}$ Research Institute for Intelligent Computer Systems, 2014. All rights reserved.
\end{abstract}

Keywords: project success, model, entrepreneurship, context, organization development.

\section{INTRODUCTION}

The success of development projects and programs depends on two groups of factors: (i) the competence of organizations in managing of its projects and programs; (ii) "Entrepreneurial spirit" that is formed by the leadership of the organization and by the initiator of the project, and which support progress towards successful completion of the projects. The success of the project, as a management category, has contradictions which are formed as a result of different views of the parties concerned [1,2]. Thus, each of the key party concerned has its level of competence in project management, and may have diametrically opposed views on the success of the projects and their products.

Entrepreneurial energy of various concerned parties promoting the project contains contradictions which are to be accounted for by the organization's leadership in project management processes. Entrepreneurial energy depends on "entrepreneurial potential" available in the organization and the key concerned parties. It is a set of orientations for success, individual and collective responsibility, freedom of expression and creativity [4]. Entrepreneurial potential is a socio-determined set of features and capabilities for organizing and operating a business, which entrepreneurs could possess [3]. Most often, the business potential is characterized by such properties as efforts to promote economic innovations, forms of implementation of the role function, the final product of economic creativity, ability to take risks, creativity, leadership ability as an entrepreneur, and individual psychological characteristics of the entrepreneur as management skills, independence in the selection and decision-making ability to respond to changes in the economic and social situation [9]. Special interest management by entrepreneurial energy takes place in information technologies [7] and Agile \& Kanban methodology for Start Up projects [5].

Summing up all these definitions and properties in the category of concepts and tools for project management, we should note that the entrepreneurial potential determines the technological maturity and organizational competence in the management of projects, programs and portfolios of projects $[8,11]$. 


\section{STATEMENT OF THE RESEARCH PROBLEM}

In the practice of project management, the term "entrepreneurial potential" is used often instead of "entrepreneurial energy", which, in fact, reduces the meaning and application of the latter.

The potential is an indicator that characterizes the reserve of energy (including business energy).

In this article, we will use the generalized definition of energy. Energy (or work) is a mathematical expression which is numerically equal to the power of the object (work) multiplied by the time of the process. Thus, we will consider the power as a quantitative measure of the inertia of the object, based on the work produced and consumed resources per one unit of time.

As the power associated with the cost of enterprise resources in the process of project implementation, the entrepreneurial energy is different from the entrepreneurial potential which characterizes only reserve of those resources.

Entrepreneurial energy is generated and reproduced through internal and external sources. Set of entrepreneurial energy sources can be mathematically modeled by means of a set equipped with additional mathematical structures (metrics, topology, etc.). This is the most common approach.

System model of development projects in a general approach to the use of business energy will include absolutely heterogeneous concept reflecting energy sources, its transmitters (amplifiers, transformers, etc.) and users (projects and programs).

The item of these studies is formulated as a project management for development of organizations through the creation and reproduction of entrepreneurial energy of the parties concerned under operational and project activities of the organization in order to build effective mechanisms for the development of the organization.

\section{CLASSIFICATION OF ENTREPRENEURIAL ENERGY}

To study the mutual influence of entrepreneurial energy and project for development of organizations, a system of indicators of its condition and sources of forming the initial energy and renewable energy development should be identified.

To date, no method for assessing entrepreneurial energy for development programs exist. Evaluation of energy for development should be based on a hierarchical system of indicators (or a system close to it). The starting point for such a system of indicators should be a system of common values which will form the mobile context for development of organizations [10].
Let's consider the classification of entrepreneurial energy in the context of modern concepts of development of organizations $[6,8]$.

In its structure, entrepreneurial energy is multidimensional. The main factors that shape the classification system are: types of entrepreneurial energy, sources and types of energy carriers, catalysts and inhibitors of the application of entrepreneurial energy in development projects, as well as indicators of the impact of the environment (context).

As for the types of entrepreneurial energy, it can be identified: the primary entrepreneurial energy (potential) and the reproducible entrepreneurial energy. The renewable energy is usually formed in the course of the project.

When classified by energy Resources, the three groups maybe distinguished: financial and other resources that are invested in the program, knowledge and creative technologies used as catalysts of entrepreneurial energy management leadership and motivation parties concerned.

As for the Sources of entrepreneurial energy, it is possible to define the following classification features: external, internal, resource, technological, behavioral (motivational). Thus, resort, technological and behavioral characteristics may refer both to internal and external sources.

In the direction of the classification of Financing, the following features can be distinguished: external investment financial resources, domestic financial resources and other resources.

In the direction of Knowledge and Creative Technologies, we can define the following attributes-external and internal intellectual property (patents, trademarks, etc.), open innovation technology and know-how.

In the direction of Leadership and Motivation, we define the following features: management leadership, motivation of the parties concerned.

\section{COMPETENCE-BASED APPROACH TO MANAGEMENT OF ENTREPRENEURIAL ENERGY FOR DEVELOPMENT PROJECTS}

Now, the terms "the energy of change" or "the energy of reformation" are often used in practice. In this case, the analogy with the motion in mechanical systems is used intuitively. Thus, energy is defined as a scalar physical quantity, as a general quantitative measure of movement and interaction of all forms of matter.

Under the term "the entrepreneurial energy", we will understand the visible and invisible activity of the actions of the project and other key concerned parties with using key resources, including 
knowledge, technology, and creative leadership, which provide progress of the project.

The presence of polar views on the existence and impact of entrepreneurial energy to the successful implementation of development programs were due to differences in the understanding of what the entrepreneurial energy means in the management of projects and programs.

Outside and external sources of entrepreneurial energy, leadership, intuition, rational thinking, appropriate emotions, needs, moods, associations and others may be included here. This set of characteristics can be modeled mathematically by means of a multitude endowed with additional mathematical structures (metrics, topology, etc.). Let's apply the hypothesis of the unity of entrepreneurial energy for sustainable balanced development of the organization based on the chosen strategy. However, under such general approach, the concept of the energy business will include completely different elements, such as energy sources, energy transmitters, amplifiers or transformers of energy.

In the development, the internal and external context of the organization plays an important role. By context, we will understand the behavior of the environment and system of contextual competences of the project team [2], which links the activities of project management and operational activities of the organization. The operating activity of the organization is its activity aimed to produce products or services. In the development of contextual competences in project and program management, mobile context is formed, which is fueling the development of projects and operations of the organization. The theme of this research is formulated as a definition of the relationship of entrepreneurial energy, mental space and mobile context of operating and project activities of the organization for establishing effective mechanisms for the development of organizational competence and competitiveness.

The entrepreneurial energy in the management of projects and programs is often by enhanced by catalysts and hampered by inhibitors.

Catalysts and inhibitors of entrepreneurial energy have their own structure. Elements of the structure of catalysts are: the presence of the special function commercialization of key decisions, the system of incentives for innovators based on the distribution of values obtained in the course of project implementation, metrics for values evaluation and integrated information for decision-making.

Inhibitors of development projects inhibit the formation and restoration of entrepreneurial energy and have their certain structure. Examples of inhibitors may be "the belief that innovation will be implemented by itself", "the creation of development policy, forms the barriers to innovation", "sending all the problems to innovators" and others.

Structure of catalysts and inhibitors are complementary elements of the evaluation model for entrepreneurial energy of an organization in a particular situation.

Exploring a new class of energy, such as "entrepreneurial energy" in organizational systems, as a rule, the studies are concentrated on the psychology of the parties concerned and technical aspects of the implementation of development projects, the investment component, the economy of production and development projects.

Creating entrepreneurial capacity, the formation and reproduction of entrepreneurial energy are based on the incremental implementation of development projects and programs.

The hypothesis in this model is used under conditions where the entrepreneurial potential of the project will be formed on the pre-investment phase of the project, during the formation of the project team and key concerned parties.

To assess the entrepreneurial capacity of the organization in the field of project management, programs and project portfolios (PP\&P), let us consider a model of organizational competence IPMA OCB $^{\circledR}$ [5].The basic principles of construction of this model are: completeness of description of the competencies for management of $P P \& P$, their integrity and consistency, independence from the assessment system of organizational competence.

The key concept of the model is the organization's focus on the next development spiral: Competence $>$ Efficiency of Activity> Competitiveness. Thus, the organizational competence is divided into five classes IPMA OCB $^{\circledR}[8]$.

Based on the previously mentioned principles, IPMA OCB ${ }^{\circledR}$, Model of Organizational Competence, systematically displays all aspects of the organization's project activity, determines the necessary connections within the administration and management of projects, programs and project portfolios, takes into account the internal and external context. Thus, the model represents the process of converting of the mission, vision and strategy into results of projects and programs. The general scheme of the conceptual model, which was developed by the authors for the development of IPMA Delta $^{\mathbb{B}}$, is shown in Fig. 1. 


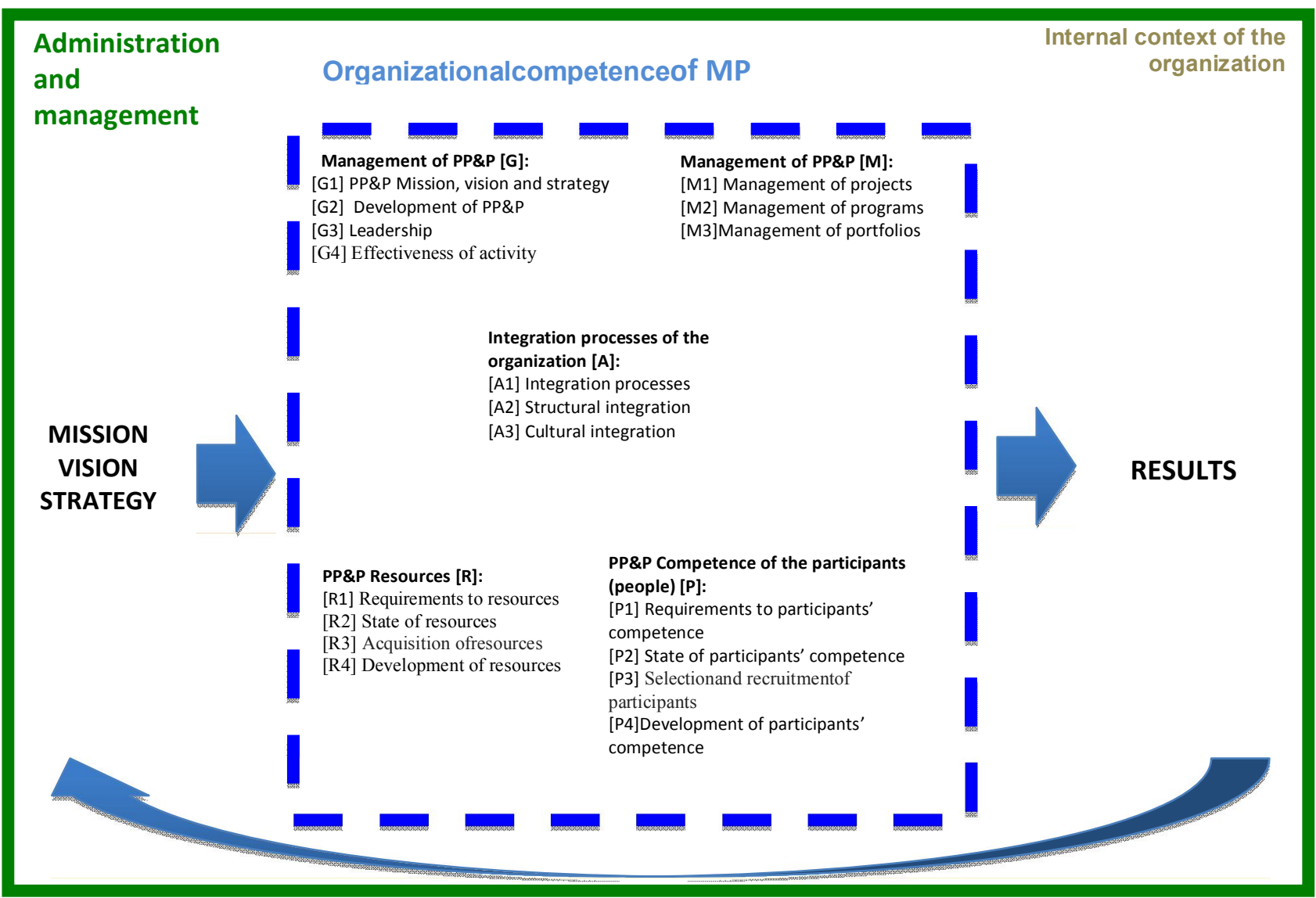

Fig. 1 - Conceptual model for evaluating organizational competence IPMA OCB ${ }^{\circledR}$.

Organizational competence in the management of projects, programs and portfolios (PP\&R) is determined within 5 expert areas: Administration of PP\&R, Management of PP\&R, Human Resources, Material Resources and Integration Processes, Structure of Culture.

Let the organizational competence will be determined by the five areas:

$$
K=<k 1, k 2, k 3, k 4, k 5>.
$$

Each area contains a number of elements (Fig. 1).

For example, the area of 'Administration of PP\&P':

$$
k 1=\{G 11, G 12, G 13, G 14\} .
$$

Thus, the estimation model of the area is formed by the R1 ratio and all of its elements. This relationship forms the convolution rule for evaluations of each competence element in the area.

All the elements of organizational competence displayed in the context of the three axes (A): Strategic (S), Tactical (T) and Operating (O):

$$
A=<S, T, O>\text {. }
$$

The generated three-dimensional space determines the trajectories for development of organizational competencies [1].

Complete description of all elements of the organizational competences model is given in IPMA OCB $^{\circledR}$ Standard.

In assessing of entrepreneurial potential (potential entrepreneurial energy) for a development project or program, the basic sources of Gorganizational competence in the management of PP\&P, investments, resources, applied creative technologies and leadership of key concerned parties should be taken into account. Each of them is determined by specific gravity $\left(V_{G}\right)$ and the impact on the success $\left(S_{G}\right)$. The parameter of influence on the success of development projects and programs is an integrated index, which is to be determined in expert way.

The level of the potential (initial) entrepreneurial energy is defined as:

$$
E_{i}=\sum_{k=0}^{G} V_{i k} S_{i k},
$$

where $i=\overline{1,4}$. 
The level of the reproducible entrepreneurial energy is determined basing on the following relationship:

$$
K_{r}=\sum_{k=0}^{G} V_{r k} S_{r k}
$$

where $r=\overline{1,4}$.

Specific gravity and impact on the success of development projects, their catalysts and inhibitors are based on expert assessments, and processed on the basis of qualimetry; they give the total normalized result of entrepreneurial energy at each phase of the project.

It follows from the applied analogy and from the definition of the potential and kinetic (reproducible) entrepreneurial energy that their level must be greater than one within all phases and steps.

Given catalysts and inhibitors, level of entrepreneurial energy is defined as:

$$
E_{C}=E_{i}+K_{r}+E^{K}+E^{I}
$$

where $E^{K}$ - normalized level of influence of catalysts to the entrepreneurial energy; $E^{I}$ - normalized level of influence of inhibitors to entrepreneurial energy in the implementation of development projects.

\section{CONCLUSIONS}

The proposed classification of entrepreneurial energy organization allows creating basic terminology and models of successful projects and programs based on entrepreneurship.

The evaluation model of business activity on the basis of the IPMA OCB ${ }^{\circledR}$ Standard allows assessing both the initial and reproducible entrepreneurial energy of the organization.

\section{REFERENCES}

[1] M. Y. Azarov, F. O. Yaroshenko, S. D. Bushuyev, Innovative Mechanisms for Managing of Development Programs, Kyiv: 'Sammit Knyga', 2011, 564 p. (in Russian)

[2] F. O. Yaroshenko, S. D. Bushuyev, H. Tanaka, Management of Innovative Projects and Programs on the Basis of P2M System Knowledge, SPb., Nauka i Tekhnika, 2013, 304 p. (in Russian)

[3] Y. F. Yaroshenko, R. F. Yaroshenko, Model Driving Forces of Resistance Models in Management of Projects and Programs, Kyiv: 'Sammit Knyga', 2010, 160 p. (in Ukrainian)

[4] M. V. Grachev, Entrepreneur in Today's Economy, Science and Economy, (4) (1993) pp. 28-40. (in Russian)
[5] R. Polk, Agile \& Kanban in Coordination, in Proceedings of IEEE Agile Conference, Salt Lake City, UT, 7-13 August 2011, pp. 263-268.

[6] H. Kerzner, Strategic Planning for Project Management Using a Project Management Maturity Model, John Wiley \& Sons Inc., 2001.

[7] ISO/IEC 12207:2010, Information technologies. Software life cycle processes, ISO/IEC, 2010, pp. 61.

[8] IPMA Organisational Competence Baseline (IPMA OCB), IPMA, 2013, $67 \mathrm{p}$.

[9] ICB. IPMA Competence Baseline, IPMA, 2006, $200 \mathrm{p}$.

[10] K. Forsberg, H. Mooz, H. Cotterman, Visualizing Project Management, $3^{\text {rd }}$ edition, John Wiley and Sons, New York, NY, 2005, $480 \mathrm{p}$.

[11] Organizational Project Management Maturity Model (OPM3): Knowledge Foundation, Project Management Institute, Newtown Square: PMI, 2003, 179 p.

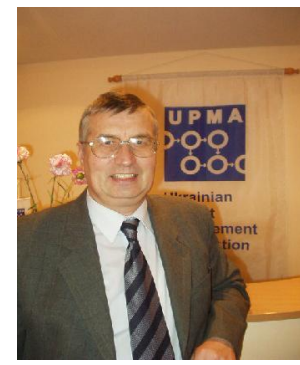

Sergey Bushuyev, PhD, Dr. Sc., Professor at Kyiv National University of Construction and Architecture (KNUCA) in Kyiv, Ukraine, Honorary Scientist of Ukraine, Laureate of National Scientific Award, Honorary member of IPMA. Sergey Bushuyev, PhD, is Head of the Department of Project management at KNUCA, specializing in Strategic Project Management and Organizational Development. He is also founder and President of the Ukrainian Project Management Association (www.upma.kiev.ua) and founder of the Project management Academy in Ukraine (1999).

$\mathrm{He}$ studied at Kyiv Engineering-Construction Institute, faculty of Automation and Information Technology (1970), PhD (1973), Dr. Sc. (1986), Professor (1988), and honorary Scientist and Technician of Ukraine (2003). He served as Founder and President of the Ukrainian Project Management Association (UPMA) (1993); active member of the New York Academy of Sciences (1996); Head of Project Management Department (1997); Adjunct Professor at University of Technology Sydney, Australia (2002); visiting Professor at ESC Lille, France(2003); Member of Certification Validation Management Board of the International Project Management Association - IPMA (1997); Ukrainian Academy of Sciences - Active member (2003); and St. Petersburg Academy of Engineering Science (Russia, 1998) - Active member.

Dr. Bushuyev has published more than 200 scientific books and articles. He is a member of the editorial board of the International Journal of Project Management published by IPMA, and for several other national and international Journals. He has 
read lectures and taught courses at Bremen University in Germany; at the Economic Development Institute of the World Bank in Washington, DC, USA; at the Bratislava Technical University in Slovakia; at Strasclaide University of Glasgow, Scotland in the UK; in the Total Quality Management program in Sweden; at the Vienna University of Economics and Business Administration in Austria; at the Lograno University in Spain; Poland University of Business Administration; and at Brno University in the Czech Republic.

Since 1975, Dr. Bushuyev has prepared 40 Candidates for Science (Ph.D.) and Doctor of Science in Development Information Management Systems and Project Management. Since 1996 he has been responsible for preparing more than 1500 candidates for Masters of Science degrees in Project Management. Recipient of an Award as the best professor of Ukraine in 1987.

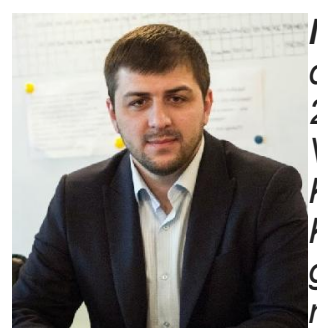

Magomed Ozdoyev is finance director of Kusto Agro Ltd. since 2013. Company is situated in Vinnitsa, Ukraine. He studied in KIMEP University city Almaty, Kazakhstan until 2006. After graduation University he was managing director of energy

and agro projects in Russia, Kazakhstan and Ukraine. He is certified project manager IPMA Level C. He is a member of Ukrainian project management association. 